\title{
GÉNERO Y LITERATURA HISPANOAMERICANA
}

\author{
MARÍA CABALLERO WANGÜEMERT \\ Universidad de Sevilla
}

\section{MUJER Y CANON LITERARIO}

Las discusiones sobre el género han teñido los últimos cincuenta años ${ }^{1} \mathrm{y}$ es obvio que los estudios sobre mujer están intrínsecamente relacionados con los conceptos de "minoría», "marginalidad»y «multiculturalidad» que, con salvedades, van aparejados al género. Como es bien sabido, ya en los setenta las Naciones Unidas proclamaron el Año Internacional de la Mujer (1972) y la Década de la Mujer (1975-1985) y, a partir de entonces, se sucedieron las conferencias mundiales para abordar la marginación femenina a todos los niveles. El asunto, sobradamente aireado por los medios de comunicación, es un simple marco que escapa a las pretensiones de mi trabajo, más interesado en el influjo que los estudios de género han tenido en el desarrollo de la literatura hispanoamericana en los últimos tiempos. Ciñéndome al campo literario, la irrupción de Woman Studies, Seminarios e Institutos sobre la Mujer ha sido un fenómeno característico de las tres últimas décadas, paralelo a la explosión de los diversos feminismos que, en realidad, venían de atrás y fueron cambiando de enfoque ${ }^{2}$. Podrían señalarse como testigos impertérritos de la evolución y modos del feminismo en literatura PMLA, Diacritics, Tel Quel, New Literary History o Critical Enquiry, por citar los más internacionales.

Poner orden en esta maraña es para mí casi imposible en las pocas páginas de un artículo. Por eso, utilizaré las voces de otras, por ejemplo Elaine Showalter, quien realiza una primera demarcación, básica pero necesaria al neófito:

«Existen dos modalidades definidas de crítica feminista, y fusionarlas (...) conduce a una perplejidad permanente ante sus potencialidades teóricas. La primera modalidad es ideológica; se ocupa de la feminista como lectora, y ofrece lecturas feministas

1. Cfr. CAZURRO GARCÍA de la QUINTANA, Carmen (ed.): La cuestión del género literario y la expresión femenina actual, Aguadilla, Puerto Rico, 1998.

2. Cfr. OlIVARES, Cecilia: Glosario de términos de crítica literaria feminista, México, El Colegio de México, 1997. 
de textos que examinan las imágenes y estereotipos de la mujer en la literatura, las omisiones y falsos conceptos acerca de la mujer en la crítica, y el lugar asignado a la mujer en los sistemas semióticos (...). La segunda modalidad de crítica feminista (...) es el estudio de las mujeres como escritoras, y sus objetos de estudio son la historia, los estilos, los temas, los géneros y las estructuras de la escritura de mujeres; la psicodinámica de la creatividad femenina; la trayectoria individual o colectiva de las carreras de las mujeres y la evolución, así como las leyes, de la tradición literaria femenina. No existe un término en inglés para este discurso crítico especializado, así que he inventado el término "ginocrítica» ${ }^{3}$.

Efectivamente, tras el cuestionamiento de las «imágenes de mujer» por el que se enfocó la primera crítica anglosajona ${ }^{4}$, The Female Imagination (1975), de Patricia Meyer Spacks; Literary Women (1976), de Ellen Moers; A Literature of Their Own (1977) de la misma Showalter; Woman's Fiction (1978), de Nina Baym; The Madwoman in the Attic (1979), de Sandra Gilbert y Susan Gubar; Women Writers and Poetic Identity (1980), de Margaret Homan, o Splintering Darkness: Latin American Women Writers in search of themselves (1990) editado por Lucía Guerra... por citar algunos de los más famosos, son libros en los que la escritura femenina se afirma como centro de los estudios feministas. Lo mismo sucede en Europa con Helene Cixous, Luce Irigaray y la crítica feminista inglesa. Lentamente se incorporan otros ámbitos como el italiano ${ }^{5}$. Al comentar este torrente bibliográfico, Showalter establece cuatro modelos que dan lugar a otras tantas orientaciones de crítica ginocéntrica: lo biológico ${ }^{6}$, lo lingüístico ${ }^{7}$, lo psicoanalítico ${ }^{8}$ y lo cultu-

3. SHOWALTER, Elaine: "La crítica feminista en el desierto", Otramente: lectura y escritura feministas, coord. Marina FE. México, Fondo de Cultura Económica, 1999, pp. 78 y 82. Es interesante su labor de coordinación en The New Feminist Criticism: Essays on Woman, Literature and Theory, New York, Pantheon Books, 1985. Por lo que se refiere al libro coordinado por Fe, forma parte de los trabajos del Seminario Interdisciplinar de Escritura Femenina, dentro del Programa Universitario de Estudios de Género de la Facultad de Filosofía y Letras de la UNAM en México.

4. Cfr. KOPPELMAN CORNILLON, Susan (ed.): Images of Women in Fiction: Feminist Perspectives, Ohio, Bowling Green University Popular Press, 1971; MILLER, Beth: Women in Hispanic Literature. Icons and Fallen Idols. Berkeley, University of California Press, 1983. El asunto no es privativo de la crítica anglosajona. Cfr. SALGUES de CARGILL, Maruxa. La imagen de la mujer en las letras hispanoamericanas: enfoque feminista de la literatura hispanoamericana, Jaén, 1975; y FOUQUES, Bernard y MARTÍNEZ GONZÁLEZ (eds.): Imágenes de mujeres, Caen, 1998.

5. Cfr. PERASSI, Emilia: Tradizione, innovazione, modelli. Scrittura femminile del mondo iberico e americano, Roma, Bulzoni, 1996.

6. Cfr. GILBERT, Sandra My GUBAR, Susan: The Madwoman in the Attic: The Woman Writer and the Nineteenth Century Literary Imagination, Yale, University Press, 1979. Hay traducción española: La loca del desván. La escritora y la imaginación literaria del siglo XIX, Madrid, Cátedra Feminismos, 1998; y RICH, Adrienne: Of Woman Born: Motherhood as Experience and Institutio, New York, W.W. Norton, 1976. La experiencia del cuerpo y la maternidad son ejes sobre los que pivota la escritura, como en Tiempo de espera, de Carme RIERA (Barcelona, Lumen, 1998). Antologías como Madres e hijas, de Laura FREIXAS son significativas en este sentido. Cfr. a propósito de la maternidad: Feminist Studies, 4 (junio 1978).

7. Cfr. POMEROY, Sarah B: Goddesses, Whores, Wives and Slaves: Women in Classical Antiquity, New York, Schocken Books, 1976.

8. En la línea freudiana o jungiana, se enfocaría hacia las tortuosas relaciones madre/hija o insistiría en la solidaridad femenina, que puede derivar en ocasiones hacia el lesbianismo. Cfr. DAVID- 
$\mathrm{ral}^{9}$. Cuerpo de la mujer/cuerpo de la escritura, la conveniencia y posibilidad/o no de un lenguaje propio, las herencias y ligazones al padre y la problemática relación con la madre, así como el deseo de recuperar y cultivar una cultura de las mujeres -por fin- son otras tantas brechas por las que discurre la investigación.

Todo ello implica que, si tradicionalmente se hablaba de que la mujer estaba ausente no ya del canon sino incluso del corpus de la literatura hispanoamericana ${ }^{10}$, ahora su presencia es un hecho incuestionable, fruto de una serie de circunstancias que pusieron sobre el tapete la figura y la problemática femenina. Como botones de muestra, un conjunto de libros-actas de congresos o números de revista de los últimos veinte años: La sartén por el mango. Encuentro de escritoras latinoamericanas ${ }^{11}$, Nuevo Texto Crítico ${ }^{12}$, Revista Iberoamericana ${ }^{13}$, Canción de Marcela. Mujer y cultura en el mundo hispano ${ }^{14}$, La escritora hispánica ${ }^{15}$, Simposio Internacional Mujer y Sociedad en América (1988). Mujer y sociedad en América ${ }^{16}$, Caribbeam Studies ${ }^{17}$, Mujer y cultura en la Colonia hispanoamericana ${ }^{18}$... Incluso un par de números extraordinarios de Universidad de México ${ }^{19}$ abordan la cultura femenina con enfoques divergentes, antitéticos o complementarios. Y no deja de llamar la atención que la prensa no especializada dedique cada vez más espacio al asunto. Buen ejemplo de ello es la Revista Hispánica Moderna en la que destacan cuatro artículos en el número de junio del 97 y seis en el de diciembre del 98.

En este conjunto de estudios no todo es género, evidentemente, si bien este asunto del género en la literatura hispanoamericana está muy unido a la revisión del canon a que la crítica se vio obligada en el último tercio del pasado siglo ${ }^{20}$. En efecto, los setenta contemplan la revolución del canon a partir de

SON, Cathy M. y BRONER, E. M.: The Lost Tradition: Mothers and Daughters in Literature, New York, Frederick Ungar, 1980.

9. Cfr. DOUGLAS, Ann: The Feminization of American Culture, New York, Alfred A. Knopf, 1977; BAYN, Nina: Woman's Fiction: A Guide to Novels by and about Women in America 1820-1870, Ithaca, N.Y., Cornell University Press, 1978.

10. Escribí hace algunos años un par conferencias de divulgación acerca de lo que comento. Cfr. CABALLERO; María: «La mujer en la literatura hispanoamericana», Femenino plural. La mujer en la literatura, Pamplona, EUNSA, 1998, pp. 29-58.

11. Edición de Patricia Elena GONZÁLEZ y Eliana ORTEGA, Río Piedras, Huracán, 1984.

12. Stanford, 4 (1989).

13. Número especial dedicado a las Escritoras de la América Hispánica, dirigido por Rose MINC. Pittsburgh, 51 ( julio-diciembre 1985), 132-133.

14. Madrid, Orígenes, 1989.

15. Coord. Nora ERRO ORTHMANN y Juan Cruz MENDIZÁBAL. Miami, Universal, 1990.

16. Westminster, Instituto Literario y Cultural Hispánico dirigido por Juana ARANCIBIA, 1990.

17. Río Piedras, Puerto Rico, 28 (enero-junio 1995), 1.

18. Ed. Mabel MORAÑA. Pittsburgh, Biblioteca de América, 1996.

19. Revista de la UNAM (México): Materiales, mujeres, materiales (1998) y Mujeres: asunto ancestral, ideas nuevas (1998).

20. He dedicado al asunto un trabajo del que éste es una variante. Lo presenté en el marco del Congreso Internacional del Instituto Internacional de Literatura Iberoamericana de Pittsburgh (IILI) celebrado en Salamanca en junio del 2001. Las actas se publicaron en CD-Rom: Carmen 
estudios como los de Rincón, Mignolo, Pizarro o Jean Franco. El cambio de la noción de literatura (1978), de Carlos Rincón ${ }^{21}$ pone sobre el tapete las tensiones que desgarran una literatura de gran desarrollo y reconocimiento internacional, pero cuyos baremos canónicos excluyen en gran medida fenómenos como el testimonio o la oralidad a veces ligados a la mujer. Entre el canon y el corpus. Alternativas para los estudios literarios y culturales en y sobre América Latina, conferencia recogida hoy en Nuevo Texto Crítico ${ }^{22}$, pasa revista a la crítica sobre el Nuevo Mundo durante los ochenta, con una conclusión interesante: proyectos críticos como los de Ana Pizarro ${ }^{23}$, Jean Franco, Rama ${ }^{24}$, Lienhard ${ }^{25}$ y González Echavarría ${ }^{26}$ desarbolan la idea tradicional de que «las esencias culturales estarían representadas por un canon (cuando en realidad) no son representadas por el canon sino creadas y mantenidas por él» (p. 24). Un planteamiento interesante y fácilmente relacionable con las cuestiones de género en las que hoy suele huirse de los esencialismos... En este proceso de ensanchamiento canónico, la inclusión de la literatura en los discursos culturales y el impacto de las teorías postcoloniales, han supuesto un incremento notable de los estudios sobre literatura femenina y género ${ }^{27}$.

\section{GÉNERO Y LITERATURA HISPANOAMERICANA}

Me interesa prioritariamente examinar cómo evoluciona la literatura en lo que se refiere a la mujer y cómo influye toda la teoría del género sobre ese específico corpus hispanoamericano. Por eso, de entre los proyectos críticos arriba citados aludiré al de Franco, plasmado en su libro Las conspiradoras. La representación de la mujer en México (versión actualizada) ${ }^{28}$ y que articula las relaciones entre la letra y lo femenino desde la Colonia hasta hoy para concluir que, salvo Garro y Castellanos, existe una relación directa entre escritura femenina y géneros discursivos no canónicos. En la primera parte de su estudio, más in-

RUIZ BARRIONUEVO y otros (ed.) La literatura iberoamericana en el 2000. Balances, perspectivas y prospectivas. Ediciones Universidad de Salamanca, 2003.

21. Bogotá, Instituto Colombiano de Cultura, 1978.

22. Stanford (junio 1995), 14-15. Recoge varias aportaciones interesantes en torno a la literatura de mujer.

23. América Latina: Palabras, literatura y cultura, 1992. Se trata de una historia de la literatura colectiva en tres volúmenes, en la que se reconsidera el canon desde un corpus mucho más amplio del habitual: tradiciones orales, una fuerte presencia de literatura femenina, productos culturales híbridos de la Colonia... Se incluye el Caribe -francés e inglés-y las literaturas fronterizas de los Estados Unidos.

24. México, Siglo XXI, 1982.

25. La voz y su huella. Escritura y conflicto étnico-social en América Latina (1492-1988. Hanover, Ediciones del Norte, 1991.

26. Myth and Archive: Toward a Theory of Latin American Narrative, New York, Columbia University Press, 1990.

27. Para otros aspectos de la crítica actual, feminista o femenina, cfr. Revista Iberoamericana, Pittsburgh, 52 (julio-diciembre 1996), pp. 176-177.

28. México, Fondo de Cultura Económica, 1993. Se publicó en inglés bajo el título Plotting Women. Gender and Representation in Mexico, New York, Columbia University Press, 1989. 
novadora, demuestra cómo la lucha de la mujer por el poder durante la Colonia se focaliza en cartas, confesiones e historias de vida de monjas recluidas en los conventos virreinales. La autora no pretende realizar una historia de la escritura femenina en México, sino ...»descubrir los momentos incandescentes en que se iluminan fugazmente distintas configuraciones de la lucha por la interpretación ${ }^{29}$. Porque, posteriormente, esas mujeres que apoyaron eficazmente las guerras de Independencia americana, al menos en México no tienen una presencia tan marcada durante el siglo XIX, el siglo de la nacionalidad.

Por cierto que el proyecto de nación implicaba una mujer ángel del hogar, y las conexiones entre ambos motivos son objeto de la crítica en la última dé$\mathrm{cada}^{30}$. En Siglo XIX: Fundación y fronteras de la ciudadanía, número de la Revista Iberoamericana dedicado a esta cuestión ${ }^{31}$, encontramos extensos trabajos en esta línea. El de Nina Gerassi-Navarro, La mujer como ciudadana: desafíos de una coqueta en el siglo XIX ${ }^{32}$, al reivindicar la actuación y escritura de una colombiana ilustre, Soledad Acosta de Samper ${ }^{33}$, hace ver la sutilidad e inteligencia de su mensaje:

«Por un lado, insiste en destruir imágenes que congelen y paralicen tanto el lugar y trabajo de los hombres como el de las mujeres. Asegurándoles a los hombres su supremacía, les recuerda que a través del hogar la mujer también tiene un rol similar al de ellos en la consolidación nacional. Por esta razón deben incluirla en todo proyecto político. Simultáneamente su mensaje se dirige a las mujeres y, cuestionando su subordinación, les incita a que trabajen por su propia valoración, que traten de hacer algo constructivo con sus vidas. La responsabilidad de la mujer es educarse justamente para poder cumplir con el mandato que le han asignado los hombres. Es por medio de este acto que la mujer puede trascender los límites de su hogar y tomar entre manos la redefinición de su rol en la sociedad» ${ }^{34}$.

El largo párrafo puede aplicarse a la labor de mujeres socialmente marginadas como Juana Manso, cuyo Album de Señoritas (1854) es rescatado hoy por Lelia Área ${ }^{35}$; o no tan marginadas, como Carolina Freyre de Jaimes que dirige $E l$ Album. Publicación Semanal, Literaria de Modas y de Costumbres (1889). Aparentemente más conservadora la mujer «tiene una misión distinta, ejerce una acción más limitada»-dirá- también reivindica para ella un "puesto en el festín del saber humano» con el que colaborar a la construcción nacional. Mujeres menos conocidas como Lindaura Anzoátegui de Campero (1846-1898) desde una posición oficialista -su esposo fue presidente de Bolivia del 80 al 84- desarrollan

29. Op. cit., p. 25.

30. Cfr. PRATT, Mary Louise: "Las mujeres y el imaginario nacional en el siglo XIX", Revista de Crítica Literaria Latinoamericana, 36 (1993), pp. 51-62.

31. Pittsburgh, 63 (enero-junio 1997).

32. Op. cit., pp.129-140.

33. Cfr. ORDÓNEZ, Montserrat: Introducción a Soledad Acosta de Samper. Bogotá, Fondo Cultural Cafetalero, 1988.

34. Op. cit., p. 132

35. ÁREA, Lelia: «El periódico Album de Señoritas de Juana Manso (1854): una voz doméstica en la fundación de una nación, Revista Iberoamericana. Pittsburgh, 63 (enero-junio 1997), pp. 149-176. 
una compleja actividad que se plasma tanto en veladas culturales como en polémicas de prensa o en el hecho de llevar la correspondencia privada del presidente. Lo que no les impide escribir novelas históricas que, en ocasiones, desafían los códigos genéricos establecidos por el discurso masculino ${ }^{36}$. La significación de mujeres como Juana Manuela Gorriti, Eduarda Mansilla de García, Mariquita Sánchez o Clorinda Matto de Turner ${ }^{37}$, está siendo revisada y reevaluada por críticos como Francine Masiello ${ }^{38}$ o Lea Fletcher ${ }^{39}$. Por no citar a las más conocidas, ya estudiadas y revisitadas por la crítica actual, como Gertrudis Gómez de Avellaneda ${ }^{40} \ldots$ En esa línea investigadora, Doris Meyer ha agrupado en un libro del 95 una serie de trabajos sobre el «ensayismo» femenino hispanoamericano durante los siglos XIX y XX ${ }^{41}$.

No se trata de ser exhaustivos, pero sí de hacer ver que el siglo XIX ha sido últimamente una etapa privilegiada en esa tarea de recuperar mujeres para la historia literaria desde ambas orillas del Atlántico ${ }^{42}$. Por cerrar este apartado y en cuanto a la literatura española se refiere, convendría recordar trabajos como los de Susan Kirpatrik sobre Las románticas ${ }^{43}$ y el volumen $\mathrm{V}$ de la Breve historia feminista de la literatura española (en lengua castellana) ${ }^{44}$ coordinada por Iris M. Zavala y centrado

36. Cfr. UNZUETA, Fernando: «Género y sujetos nacionales: en torno a las novelas históricas de Lindaura Anzoátegui», Ibídem, pp. 219-229.

37. Incluso yo misma he escrito un par de trabajos sobre esta última: uno de tipo general para la Historia de la literatura hispanoamericana publicada en Madrid por Cátedra (1987) y coordinada por Înigo MADRIGAL, pp. 219-228; y otro más específico "Clorinda Matto de Turner: el papel de la mujer entre tradición e innovación", La crítica literaria española frente a la literatura latinoamericana. Coord. FLEMING, Leonor y BOSQUE LATRA, Mª Teresa. México, UNAM, 1993, pp. 159-174.

38. En su libro Between Civilization and Barbarism. Women, Nation, and Literary Culture in Modern Argentine, Lincoln: University of Nebraska Press, 1992, que puede completarse desde otra óptica con La mujer y el espacio público. El periodismo femenino en la Argentina del siglo XIX, Buenos Aires, Feminaria ed.., 1994, compilado por ella.

39. Cfr. su trabajo editorial en Mujeres y cultura en la Argentina del siglo XIX, Buenos Aires, Feminaria ed., 1994.

40. Cfr. al respecto el reciente libro de María C. ALBIN: Género, poesía y esfera pública. Gertrudis Gómez de Avellaneda y la tradición romántica, Madrid, Trotta, 2.002.

41. Reinterpreting the Spanish American Essay: Women Writers of the 19th and 20th Centuries, Austin, University of Texas Press, 1995.

42. El trabajo más abarcador al respecto es el de ARAMBEL-GUIÑAZÚ, María Cristina y MARTIN, Claire Emilie: Las mujeres toman la palabra. Escritura femenina del siglo XIX, Madrid, Iberoamericana, 2001, 2 vols. El primer volumen es un estudio en seis capítulos de los primeros géneros o espacios que propician la escritura de las mujeres : el salón y la carta, la prensa feminista, el relato de viaje, la autobiografía, el cuento y la novela. El segundo reúne textos escritos -dentro de esos cauces- por nueve mujeres: Mercedes Cabello de Carbonera, Juana Manuela Gorriti, Rosa Guerra, Eduarda Mansilla de García, Juana Manso, Clorinda Matto de Turner, la condesa de Merlín, Manuela Sáenz y Mariquita Sánchez.

43. Las románticas. Women writers and subjectivity in Spain (1835-1850), 1989. Hay traducción española: Las románticas. Escritoras y subjetividad en España 1835-1850, Madrid, Cátedra Feminismos, 1991.

44. Barcelona, Anthropos- Editorial de la Universidad de Puerto Rico, 1998. 
en los siglos XIX y XX. O el reciente rescate de textos de la Pardo Bazán ${ }^{45}$, Carmen Baroja ${ }^{46} .$. -en el lado de acá- paralelo al de mujeres como Teresa de la Parra ${ }^{47}$ o Camila Henríquez Ureña ${ }^{48}$ de la otra orilla atlántica ${ }^{49}$.

En resumen: este pequeño recorrido por una parte mínima de la amplísima bibliografía actual sobre literatura femenina hispanoamericana -género incluido- permite concluir que, al menos el corpus, se ha ampliado notablemente en las últimas décadas. Si los primeros trabajos feministas insistían en poner de manifiesto la doble marginación (mujer y mestiza) de la escritora del Nuevo Mundo y resaltaban las «tretas del débil» -en palabras de Josefina Ludmer comentando la Respuesta de Sor Juana Inés de la Cruz- en un mundo en el que se imponía la retórica de la opresión que colocaba a la mujer al nivel de cualquier marginado -indio o negro-, los de la última hornada hablan de "género» desde luego; pero teñidos de postmodernidad alertan contra los esencialismos, contra la erección de un único modelo teórico. Y se enfocan hacia una paciente labor de rescate de lo que en muchos casos suelen ser cartas, diarios, autobiografías -por ejemplo, el libro de Cristina Saénz de Tejada ${ }^{50}$ - porque, como es bien sabido, a la mujer le ha sido más fácil partir de lo privado para, desde allí, subvertir lo público. Trabajos sobre la memoria o la infancia surgen por todas partes: Fornet $^{51}$, Lagos ${ }^{52}$, Pasternac ${ }^{53} \ldots$

Si todavía en los años cincuenta la mujer como escritora estaba ausente de antologías de Colombia o Puerto Rico - por citar algunas-, a partir de los setenta comienza a incorporarse tímidamente en lo que es un proceso incontenible hasta convertirse en un boom de literatura femenina: Voces femeninas de Hispanoamérica ${ }^{54}$, Antología del cuento femenino boliviano ${ }^{55}$, Elles ècrivent des Antilles ${ }^{56}$, Del silencio al estallido: narrativa femenina puertorriqueñ ${ }^{57}$, Narradoras paraguayas

45. Cfr. PARDO BAZÁN, Emilia: La mujer española y otros escritos, Madrid, Cátedra Feminismos, 1999. Ediciones del Orto en Madrid ha abierto una pequeña colección bio-bibliográfica de sujeto femenino. Cfr. BLANCO, Alda: María Martinez Sierra (1874-1974), 1999.

46. Cfr. BAROJA y NESSI, Carmen: Recuerdos de una mujer de la generación del 98, Prólogo, edición y notas de Amparo HURTADO, Barcelona, Tusquets, 1998.

47. Influencia de las mujeres en la formación del alma americana, Caracas, Fundarte, 1991.

48. Feminismo y otros temas sobre la mujer en la sociedad, Santo Domingo, Taller, 1985.

49. Como historia de las relaciones culturales en ese sentido puede señalarse Hispanoamericanas en Madrid (1800-1936), Ed. de Juana MARTÍNEZ GÓMEZ y Almudena MEJÍAS ALONSO, Madrid, Dirección General de la Mujer y editorial Horas, 1994.

50. La reconstrucción de la identidad femenina en la narrativa autobiográfica latinoamericana (1975-1985), New York, Peter Lang, 1998.

51. FORNET, Jorge: Reescrituras de la memoria: novela femenina y revolución en México, La Habana, Letras Cubanas, 1994.

52. LAGOS, M0 Inés: En tono mayor: relatos de formación de protagonista femenino en Hispanoamérica, Santiago de Chile, Cuarto Propio, 1996.

53. Escribir la infancia: narradoras mexicanas contemporáneas. Ed. de Nora PASTERNAC, Ana Rosa DOMENELLA y Luzelena GUTIÉRREZ de VELASCO, México, El Colegio de México, 1996.

54. Ed. Gloria Bautista BENÍTEZ. Pittsburgh, University of Pittsburgh Press, 1996.

55. Selección de Manuel VARGAS, La Paz, Cochabamba, Los amigos del Libro, 1997.

56. Coord. Susanne RINNE et Joelle VITIELLO, París, L'Harnattam, 1997.

57. Ed. Ramón Luis ACEVEDO, Río Piedras, Cultural, 1991. 
$(\text { Antología })^{58} \ldots$ y tantas otras. De modo paralelo innundan el mercado libros coordinados generalmente por mujeres y que reunen una pluralidad de trabajos críticos sobre literatura femenina. A partir del clásico Women's Writting in Latin America ${ }^{59}$ coordinado por Sara Castro-Klaren, Silvia Molloy y Beatriz Sarlo, y aunque siguen publicándose trabajos generalistas ${ }^{60}$ parecen irse diversificando por países según aumenta el corpus. México es un país muy bien representado: Schaefer ${ }^{61}$, Ibsen ${ }^{62}$, López González ${ }^{63}$, Gabriella de Beer ${ }^{64}, M^{a}$ Elena de Valdés ${ }^{65}$, tuvieron a su cargo sendos volúmenes. Pero otros países tradicionalmente más atrasados se han incorporado al proceso de forma rotunda: Colombia ${ }^{66}$, Chile ${ }^{67}$ o el Caribe ${ }^{68}$. En otros casos se trata de una labor personal: una mujer se interesa por otras mujeres y publica una serie de trabajos que ha ido recopilando como fruto de su labor; es el caso de Raquel Rumeu en su libro Voces de mujeres en la literatura cubana ${ }^{69}$.

Aunque en estos libros los enfoques andan mezclados porque algunos lugares están atravesando la primera etapa reivindicativa, el contexto postmoderno conlleva hoy el replanteamiento de lo femenino como un espacio diferente y alternativo ${ }^{70}$. En ocasiones nos hallamos ante mujeres situadas dentro del sistema como críticos literarios ${ }^{71}$ que, en un momento dado, escriben una autobiografía. Estoy pensando en el texto de Silvia Molloy, En breve cárcel ${ }^{2}$, donde queda lejos lo testimonial romántico de la primera escritura femenina y el narrador cons-

58. Coord. José Vicente PEIRÓ y Guido RODRÍGUEZ ALCALÁ, Asunción, Expolibro, 1999.

59. Boulder, Colorado, Westview Press, 1991.

60. Cfr. Poéticas de escritoras hispanoamericanas al alba del próximo milenio. Ed. Lady ROJAS-TREMPE, Catharina VALLEJO, Miami, Universal, 1998.

61. Cfr. SCHAEFER, Claudia: Textured lived: women, art and representation in modern México, Tucson, The University of Arizona Press, 1992.

62. Cfr. The Oder Mirror: Women's Narrative in México 1980-1995, Ed. Kristine IBSEN, Westport, Conneticut, Greenwood Press, 1997.

63. Cfr. Mujer y literatura mexicana y chicana. Culturas en contacto, Coord. Aralia LÓPEZ GONZÁLEZ, Amelia MALAGAMBA y Elena URRUTIA, México, El Colegio de México, 1990, 2 vols.

64. Cfr. Contemporary Mexican Women Writers, 1996.

65. Cfr. The Shattered Mirror. Representations of Women in Mexican Literatura, Austin, University of Texas Press, 1998. Aborda conjuntamente miradas masculinas (Rulfo o Fuentes) y femeninas.

66. Cfr. ¿Y las mujeres? Ensayos sobre literatura colombiana. Ed. Mercedes JARAMILLO, Ángela Inés ROBLEDO y Flor María RODRÍGUEZ-ARENAS, Medellín, Universidad de Antioquia, 1991; Literatura y diferencia: escritoras colombianas del siglo XX. Ed. Mercedes JARAMILLO, Betty OSORIO de NEGRET y Ángela Inés ROBLEDO, Santafé de Bogotá, Uniandes, 1995, 2 vols.

67. Cfr. Vera LAMPEREIN, Lina: Presencia femenina en la literatura nacional: una trayectoria apasionante (1750-1990), Santiago de Chile, Cuarto Propio, 1994; ORTEGA, Eliana: Lo que se hereda no se hurta (ensayos de crítica feminista), Santiago de Chile, Cuarto Propio, 1996.

68. Cfr. The Whisthing bird: Women Writers of the Caribean. Ed. Elaine CAMPBELL y Pierrette FRICKEY, Boulder, Colorado, Lynne Rienner Publ., 1998.

69. Madrid, Verbum, 2000.

70. Cfr. BLUNT, Allison y ROSE, Gilliam (ed.): Writing Women and Space. Colonial and Postcolonial Geographies, New York, The Guilford Press, 1994.

71. Buena muestra de ello es su fundamental estudio sobre la autobiografía: At Face Value. Autobiographical Writing in Spanish America, Cambridge, Cambridge University Press, 1991.

72. Barcelona, Seix Barral, 1981. 
truye página a página su propia realidad ${ }^{73}$. Lo cierto es que no todas las mujeres van ya en el mismo cajón; entre ellas pueden establecerse ciertas relaciones de poder.

\section{EL GÉNERO Y SU INFLUENCIA EN LA CRÍTICA Y LA CREACIÓN LITERARIA HISPANOAMERICANAS}

En realidad, mucho de lo reseñado hasta ahora tiene que ver con esto, pero me gustaría ejemplificarlo a partir del comentario a una serie de textos (algunas monografías y una novela) que muestran cómo todas estas teorías han alcanzado a las escritoras del Nuevo Mundo y están en la base de muchas de sus creaciones actuales.

El primer trabajo que quiero comentar es el de Susana Reisz Voces sexuadas. Género y poesía en Hispanoamérica ${ }^{74}$. Bajo un título que acota con claridad sus intenciones reúne un conjunto de ensayos que dialogan con las fronteras que separan a hombres y mujeres desde la más obvia -el machismo, para ellos y el hambre de amor, para ellas- según un epígrafe de Isabel Allende que se glosa con inteligencia. Son ....voces femeninas que intentan derribar alambrados de púas, entrar a cotos cerrados y ensanchar los territorios tradicionales de los géneros literarios» ${ }^{75}$. ¿Femenino, feminista? Reisz contesta: se trata de obras que expresan ... «formas de experiencia específicamente ligadas a la situación de la mujer como representante del segundo sexo» ${ }^{76}$. Para añadir a continuación:

«Creo además que, dado que el género sexual -análogamente a los géneros literarios- es una construcción cultural de características y consecuencias altamente variables, sólo es posible describir el objeto poesía femenina dentro de cierta topografía social y de muy precisas coordenadas históricas. Sólo así se logra sortear el riesgo de un ingenuo (o calculado) esencialismo y dar cuenta, a un mismo tiempo, de la variabilidad de la experiencia de las mujeres en relación con el género sexual de que son portadoras y de la diversidad de las estrategias discursivas aptas para articular estéticamente esa experiencia en cada uno de los géneros literarios» ${ }^{77}$.

La cita es larga, aún así necesaria por lo representativa de un tipo de crítica literaria hispanoamericana habitualmente escrita por mujeres, que enfocan su objeto de estudio partiendo de premisas semejantes. Su lectura del corpus de poetisas latinas contemporáneas -Blanca Varela, Carmen Ollé, Susana Thénon, Gioconda Belli, Cecilia Vicuña, Rocío Silva Santisteban...- lo confirma. Se trata de textos con ... "un lenguaje y una visión de mundo marcados inequívocamente por el problemático estatuto de la mujer dentro de una cultura patriarcal» ${ }^{78}$, lo

73. Cfr. para el ámbito español MASANET, Lydia: La autobiografía femenina española contemporánea, Madrid, Fundamentos, 1998.

74. Lleida, Asociación Española de Estudios Literarios y Ediciones de la Universidad de Lleida, 1996.

75. Ibídem, p. 15.

76. Ibídem, p. 25.

77. Ibídem, p. 25.

78. Ibídem, p. 26. 
que hace interesante establecer conexiones entre determinados procedimientos textuales y el contexto sociopolítico del que han surgido. La crítica al «esencialismo» femenino se ensancha: no tiene sentido teorizar sobre si hay o no una escritura específicamente femenina. Más bien, se perfila que esa lucha femenina por acceder a un lenguaje artístico propio es una opción genérica y algo más, es también una opción política. Podría no serlo pero lo cierto es que en la Hispanoamérica convulsa del siglo veinte, heredera de corrupciones, caciquismos y dictaduras, muchas de las mujeres feministas hicieron en su momento una opción política radical.

No puedo detenerme mucho más en el comentario, pero epígrafes como «literatura femenina, literatura menor", "la voz del amo y la mirada reprobadora", "canibalismos y contra-transgresiones», "sumisión o subversión», "retóricas de la feminidad», «estilizaciones y parodias», «reescritura de géneros menores», «la fuerza de la modestia», «imágenes de un cuerpo en crisis» o "de murgas, amores transgresivos y cuestiones femeninas»... dan cuenta de temas y focalizaciones con que la investigadora se acerca a su objeto de estudio, que no es otro que las poetas peruanas y argentinas del siglo pasado. Dos apuntes nada más: hablando del tópico de la falsa modestia, no puede evitar la consabida alusión a la Respuesta a Sor Filotea y a la habilidad de Sor Juana Inés de la Cruz en ... «la sutil maniobra subversiva (que) consiste en aceptar el ámbito de lo privado y lo casero-sin-importancia como el medio natural y adecuado para el desenvolvimiento de la mujer y, al mismo tiempo, remodelar y ensanchar ese espacio hasta el límite de lo reconocible o desfamiliarizarlo hasta volverlo inquietante ${ }^{79}$. El segundo apunte tiene que ver con la relación que Reisz establece entre mujeres y melancolía -relación ya muy presente en mujeres decimonónicas como la Avellaneda, añadiría yo-. Esa melancolía es el fruto de maltratos de todo tipo. Dice al respecto:

"En muchos textos de las mejores poetas del Perú de hoy se pueden oir muy nítidamente los acentos mutuamente discordantes de un yo arrinconado y debilitado hasta la extenuación, que reclama su derecho a la autonomía, y de una voz autoritaria y hostil, colectiva pero no propia, que silencia los balbuceos del yo y le recuerda amenazante que poco le falta para ponerse vieja y poco apetecible. O que le reprocha que ya no sea joven. O que le repite que es gorda y fofa. O débil e ignorante. $\mathrm{O}$ bonita pero tonta. $\mathrm{O}$ inteligente pero fea. $\mathrm{O}$ una histérica. $\mathrm{O}$ una menopaúsica. $\mathrm{O}$ una teatrera» 80 .

Mario Cancel compiló en el 97 ocho trabajos sobre Historia y género. Vidas y relatos de mujeres en el Caribe ${ }^{81}$, que muestran el influjo de la crítica norteamericana en la Isla. Excepto el compilador, se trata de mujeres que analizan cómo afecta el género a la historiografía -en concreto a los relatos de vida-, a la sociedad-con enfoques sobre el matriarcado, la higiene, la beneficencia y el papel

79. Ibídem, p. 82.

80. Ibídem, p. 37.

81. San Juan de Puerto Rico, Asociación Puertorriqueña de Historiadores y Postdata. 
de los "ángeles de la caridad", e incluso a la teosofía-... Y todo ello dentro de un prisma de género, por supuesto, que -piensan- aportó ...»a la crítica literaria una dimensión de mayor profundidad al identificar lo femenino y lo masculino como elementos cambiantes en diferentes épocas y sociedades. La crítica del género confirma que nuestros valores y experiencias colectivas y personales inciden en nuestra lectura» ${ }^{2}$.

Son palabras de Aileen Schmidt quien, en su artículo «Los discursos autobiográficos de mujeres en Cuba y Puerto Rico» arremete contra la crítica y teoría autobiográficas por -según ella- discriminar a las mujeres. A continuación pretende ... «demostrar la existencia de una tradición femenina única, especial y distintiva de los discursos autobiográficos ${ }^{83}$. Y lo hace con un planteamiento algo reductor -para mi gusto- a partir de modelos como Sor Juana Inés de la Cruz, las crónicas de viajeras del XIX hasta llegar al testimonio del XX al modo y manera de Rigoberta Menchú. Obsesionada por no caer en la trampa de estudiar la construcción de lo femenino, sino estudiar a las mujeres mismas -dejarlas hablar-, escoge las narrativas de la cotidianidad como medio de insertarse en la historia, de hacerse un lugar en el mundo. Selecciona, entonces, textos de las puertorriqueñas Nilita Vientós Gastón, Marigloria Palma y Sor Isolina Ferré, así como de las cubanas Renée Méndez Capote, Dora Alonso y Marta González ${ }^{84}$. Y concluye:

«Las mujeres que escriben narraciones sobre sus vidas tienen frente a sí una tarea ingente: establecer la autoridad discursiva que les permitirá interpretarse a sí mismas públicamente en una cultura patriarcal y en un género literario androcéntrico. La autobiografía expone un deseo de transgresión. Al contar su vida, la mujer decide representarse a sí misma en lugar de seguir siendo objeto de la representación del hombre» ${ }^{85}$.

Eso es lo que hace en profundidad y con gran maestría Albin en su libro sobre Gertrudis Gómez de Avellaneda Género, poesía y esfera pública... ya citado. En vez de volver a divagar sobre la consabida autobiografía, es decir, las cartasdiario a Cepeda ya bastante trabajadas por la crítica, tiene el acierto de rescatar sus memorias de viaje, en que la cubana relata su aventura hacia España y el contraste entre sus expectativas y la realidad de la metrópoli, no tan brillante ni avanzada culturalmente y sin demasiados resquicios para la mujer que se sabe distinta, incluso genial -por qué no- y quiere abrirse camino literario en un mundo de hombres. Fechada el siete de noviembre de 1838, es en realidad una extensa carta a su prima y amiga Eloísa de Arteaga, destinatario obligado por su amistad. Entre Cuba -sinécdoque del Nuevo Mundo-y España -sinécdoque del Viejo-, la cubana va desgranando sus impresiones que abarcan desde las

82. Ibídem, pp. 16-17.

83. Ibídem, p. 17.

84. Textos tan disímiles necesitan de una mayor finura a la hora de abordarlos en profundidad. El trabajo es demasiado superficial y generalista.

85. SCHMIDT, Aileen: «Los discursos autobiográficos»..., op cit., p. 18. 
descripciones de una naturaleza sublime, hasta la evocación lírica de un paraíso perdido en el que tiene su centro Heredia, su padre y mentor poético, del que se citan versos y de cuya energía poética irá apoderándose paulatinamente... Las observaciones prácticas sobre transporte y aspecto de las ciudades cuando toca puerto en Francia, o los pertinentes comentarios de tipo sociopolítico conviven con su trasfondo, en el que prima el deseo de elaborar un mito de fundación.

Lo interesante de este escrito desde el punto de vista del género -y ha sido bien señalado por Albin- es la imitatio y el desvío a la vez de los relatos de viaje ilustrados de los siglos XVIII y XIX empezando por el texto canónico por excelencia: las Cartas persas, de Montesquieu y continuando por Humboldt. Ello, en realidad, tiene mucho que ver con la postura de cuestionar la autoridad... y es lo que aprende a realizar la Avellaneda, convencida de que las mujeres tienen más derechos y son más ilustradas en los países más avanzados... y no tan segura de que la metrópoli -y en concreto Galicia donde irá a vivir en primer lugar con sus parientes- lo sea. Sufrirá un doble proceso de atracción/repulsión frente a España, ofreciéndose como puente y mediadora entre ambos mundos.

Pero además, justo al desembarcar, la futura escritora inicia $S a b$, novela abolicionista escrita a lo largo de dos años a partir de 1836, y en la que establecerá un paralelismo implícito entre la esclavitud en Cuba y la esclavitud femenina en el matrimonio... A esta interpretación podrá llegar gracias a la mediación de Montesquieu como sugiere Albin:

«La filosofía política de Montesquieu ejerció una gran influencia en el pensamiento y la obra de Gómez de Avellaneda, en particular en lo que se refiere a la posición que se le adjudica a la mujer y al esclavo en la sociedad colonial y metropolitana. La escritora adopta una posición de condena a la esclavitud similar a la del pensador francés en su novela Sab»...86

La insatisfacción de Tula como mujer, su eterno conflicto entre pasiones trascendentes y deseos insatisfechos, así como la feminización del sujeto romántico en su obra ha sido bien expuesto por Kirpatrick en su libro Las románticas... ya citado: la mujer que es superior a la definición social de su sexo está condenada a la desdicha en el amor. Hay un fatum que la persigue...

Retornando al trabajo de Albin, «Fronteras de género, nación y ciudadanía: La Ilustración, Álbum de las Damas (1845) y Álbum cubano de lo bueno y de lo bello (1860) de Gertrudis Gómez de Avellaneda» analiza la labor periodística de la cubana. Una labor de cuño educativo y político, ya que plantea la capacidad de las mujeres para el gobierno apoyándose -al estilo de Sor Juana- en autoridades de la antigüedad grecolatina como Plutarco. Frente a Delmonte y su círculo abolicionista cubano, exige la presencia femenina en el proyecto político de las nuevas repúblicas.

Para terminar con este leve repaso al asunto de mujer y literatura o, mejor, al rescate de la mujer hispanoamericana al hilo del "género», me gustaría deli-

86. ALBIN, María: «Las Memorias de viaje» ..., op. cit., p. 45. 
near un breve apunte sobre el ecofeminismo, término equívoco que se pone de moda en la segunda mitad del siglo veinte y que básicamente critica el abuso humano de la naturaleza. Tal vez tuvo éxito por ese fácil paralelismo entre la explotación de lo natural y la explotación femenina ${ }^{87}$. Pero existe otro sector, uno de los más radicales entre las feministas, que heredando teorías de Simone de Beauvoir desconfía de ese volver a resucitar la "diferencia» implícita en la reciprocidad mujer-naturaleza, convencidas de que genera dependencia. Por el contrario algunos piensan que frente al machismo y al feminismo más radical, un ecofeminismo bien entendido hablaría de interdependencia y complementariedad: es la tesis de $\mathrm{M}^{\mathrm{a}}$ Antonia Bel Bravo ${ }^{88}$.

Una muestra relativamente actual de esta tendencia en Hispanoamérica es Waslala: memorial del futuro (1996), de Gioconda Belli. Viaje simbólico en la estela de la utopía, novela inscrita en una tradición testimonial y de denuncia ${ }^{89}$ explícita en múltiples referencias intertextuales. Porque la intertextualidad es la clave recurrente en una novela que reescribe conscientemente La vorágine, de J.E. Rivera y Los pasos perdidos del cubano Carpentier. Y funciona desde el deseo de construir un paradigma que entrañe una concepción del mundo: civilización/barbarie, el emblema del río símbolo de ese viaje interior, iniciático, de un personaje femenino que anhela obsesivamente alcanzar el paraíso utópico, el lugar de eterna primavera -Colón dixit- que se esconde tras el corredor de los vientos, inevitable umbral mítico. La Utopía de Moro, Ulises el eterno viajero, Platón y sus atisbos sobre la función del poeta en la sociedad... Toda la tradición occidental transferida al Nuevo Mundo se procesa en una búsqueda de cuño autobiográfico. Búsqueda femenina, teñida de orfandad: el sema del abandono paterno le llega a Belli desde otras de sus novelas, Sofía de los presagios (1994). Pero no cabe duda de que en Waslala ha superado los resquemores de la conquista más tópicamente feministas y que recorrían las páginas de La mujer habitada (1988) o, incluso la parodia de la creación bíblica que vertebra explícitamente su poemario De la costilla de Eva (1986). Y en ese sentido, ese "memorial del futuro» como "los recuerdos del porvenir» de Garro, inscribiéndose en la tradición escrituraria masculina, es capaz de forjar una escritura propia.

¿Qué proporción de ese apabullante corpus femenino potenciado por los estudios de género logrará inscribirse en el canon de la literatura hispanoamericana del 2.000? ¿Quien dictamirá al respecto? No lo sé, ni soy quién para extraer las conclusiones pertinentes. La cuestión queda abierta al debate interdisciplinar propiciado por trabajos como los que se presentan en este número de Feminismo/s.

87. Cfr. De CUNHA-GIABBAS, Gloria: «Ecofeminismo latinoamericano», Letras femeninas, Dir. Adelaida LÓPEZ MARTÍNEZ, Nebraska, 22 (primavera-otoño 1996), pp. 1-2.

88. Expuesta en el primer artículo del libro que coordina bajo el título: Ecofeminismo: un reencuentro con la naturaleza, Jaén, Universidad, 1999.

89. La explotación de los caucheros, la corrupción, la violencia de las interminables guerras y guerrillas... pero sobre todo la denuncia contra los vertidos tóxicos y un episodio real -Goianía 1987- se erigen en los principales referentes históricos. 